\title{
A Program of Budget Restraint
}

HE FEDERAL BUDGET and the Economic Report of the President were presented to Congress in mid-January. These two documents represent the former Administration's evaluation of current economic conditions and the 1969 national economic plan, and have been adopted without substantial change by the present Administration. ${ }^{1}$ The Federal budget calls for a spending increase of 5.5 per cent from fourth quarter 1968 to fourth quarter 1969, and Congress was asked to extend the 10 per cent surcharge to mid-1970. In the context of these proposals, GNP is projected to increase about 6 per cent in the year ending fourth quarter 1969.

The 1969 Economic Report and the appended Annual Report of the Council of Economic Advisers (CEA) focus on the problem of inflation. According to the CEA Report, "With inflationary pressures still strong, economic policy should continue to exert restraint in 1969 . Total demand must be brought into better balance with the nation's productive capacity to permit a slowing of price and cost increases." To achieve these objectives, the outgoing Administration outlined a fiscal program which would shift the Federal budget, on a national income accounts (NIA) basis, from near balance in late 1968 to a surplus of $\$ 3$ billion in late 1969 . With respect to monetary policy, the CEA Report suggests that such policy should generally reinforce the intent of fiscal restraint in 1969.

Appraising the 1969 economic plan is complicated by the change of administrations. Apparently the new Administration has adopted the plan of the outgoing Administration with regard to the selection of targets, but there may be some differences as to the means of achieving them. The objective of this article is to determine what insights can be gained from recent experience that may be of help in the formulation of current and future stabilization policy.

\footnotetext{
ISee the statement of the Council of Economic Advisers prepared for the Joint Economic Committee, February 17 , 1969.
}

\section{Stabilization Actions and Economic Activity in 1968}

The nation's major economic problem in 1968 was inflation, generated by an excessive demand for goods and services." Prices rose about 4 per cent during the year, compared with a 3 per cent annual rate of increase from 1965 to 1967 , and a 1.5 per cent average rate from 1961 to 1965 . Excessive total demand was fostered by expansionary fiscal conditions to mid-year and rapid monetary expansion through the year.

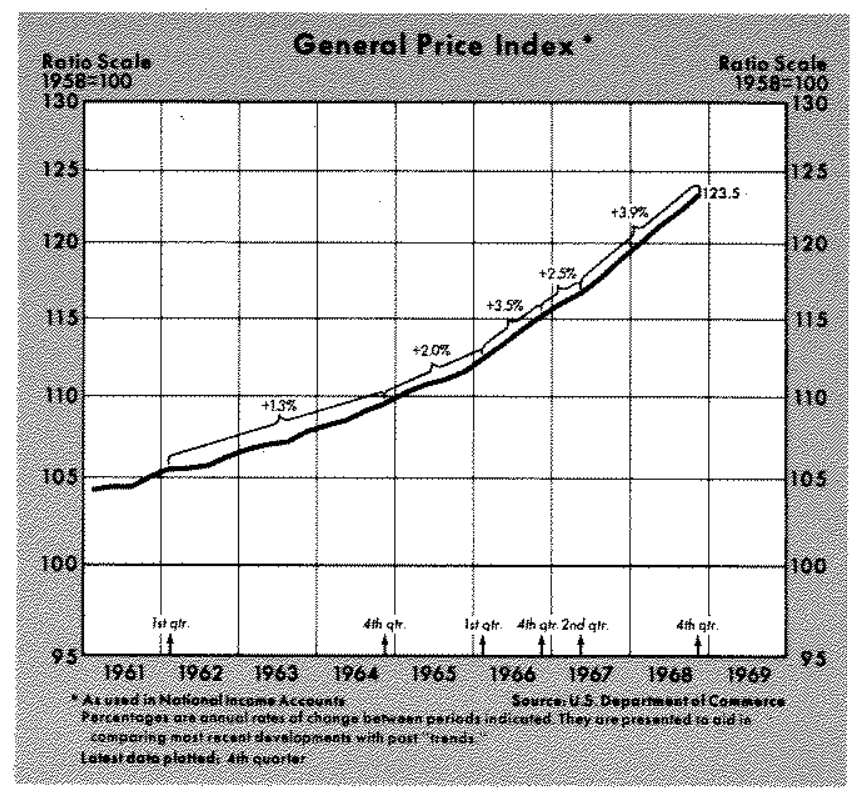

Total spending rose 9.5 per cent from late 1967 to late 1968, compared with a trend rate of 7.2 per cent from 1961 to 1967 . The 1968 rise in spending was manifested in a 5.5 per cent increase in real output and a 3.9 per cent advance in prices.

\section{Fiscal and Monetary Actions}

The Government's fiscal condition was stimulative in the first half of 1968, but became much less expansionary after mid-year, following passage

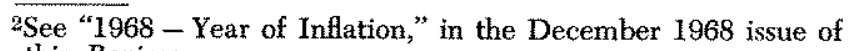
this Review.

Page 10 


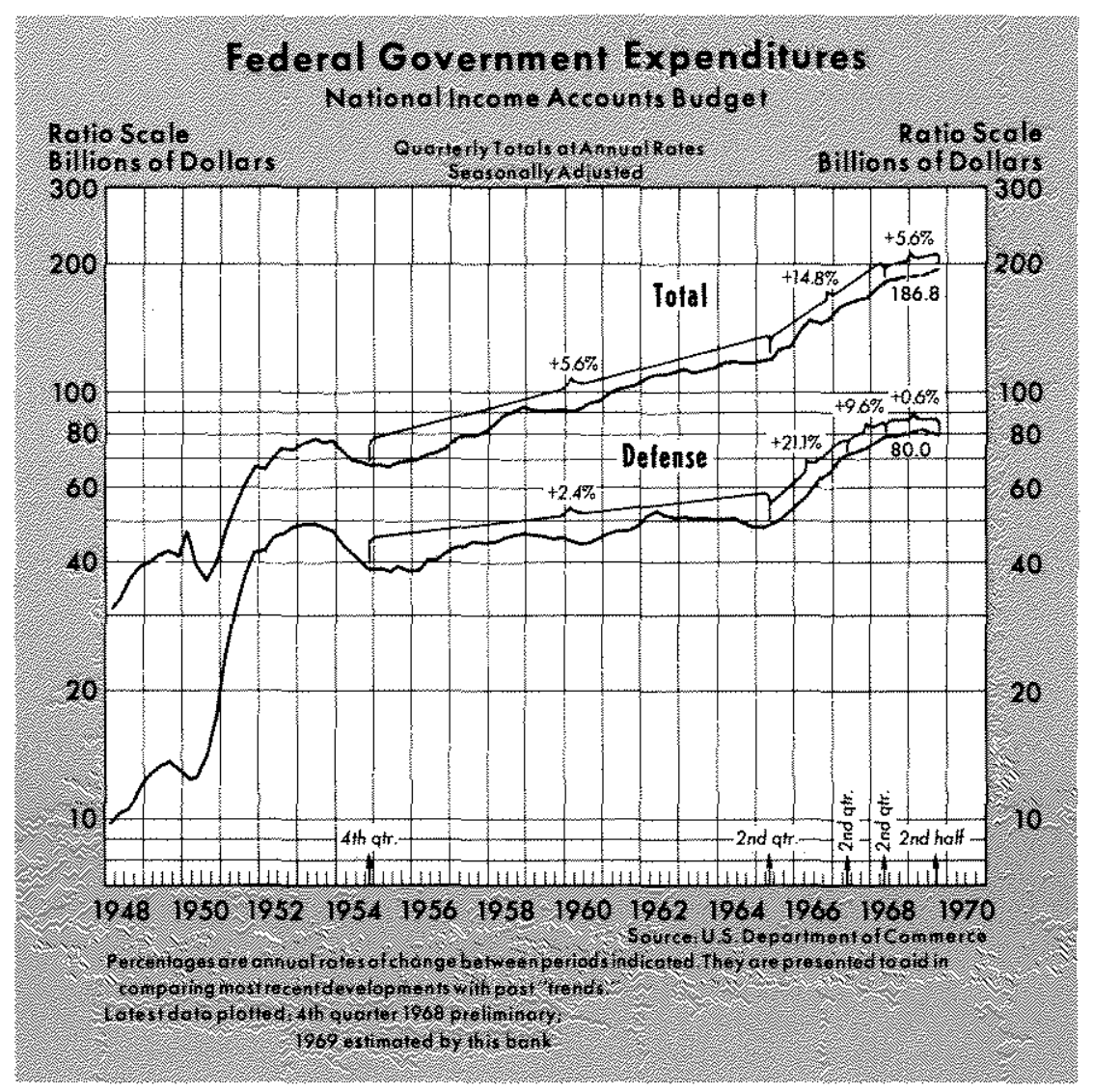

to 1967 and at a 5 per cent rate from 1961 to 1965 . Defense spending rose at a 2.5 per cent annual rate during the second half of 1968 , compared with a 12.1 per cent rate of advance in the first half and a 20.2 per cent average rate from 1965 to 1967. Nondefense spending rose in the second half of 1968 at a 7.7 per cent rate, compared with a 19.8 per cent rate in the first half and an 11.5 per cent rate in the 1965 to 1967 period.

Enactment of the 10 per cent surcharge and continued rapid advances of nominal incomes boosted the Government's tax revenues sharply during the year. Receipts (NIA basis) rose by $\$ 31$ billion from late 1967 to late 1968, $\$ 18$ billion of which resulted from increased tax rates. The remaining $\$ 13$ billion reflected the rapid advance of incomes and profits.

As Federal spending growth slowed during the year and receipts rose very rapidly, the high-employment budget

in late June of the Revenue and Expenditure Control Act of 1968. The high-employment budget shifted from a very high rate of deficit in the first half to a small surplus in the fourth quarter.

Federal spending (NIA basis) rose at a 16.4 per cent annual rate during the first half and a 5.5 per cent rate in the second half. In comparison, Federal spending rose at a 15 per cent average rate from 1965

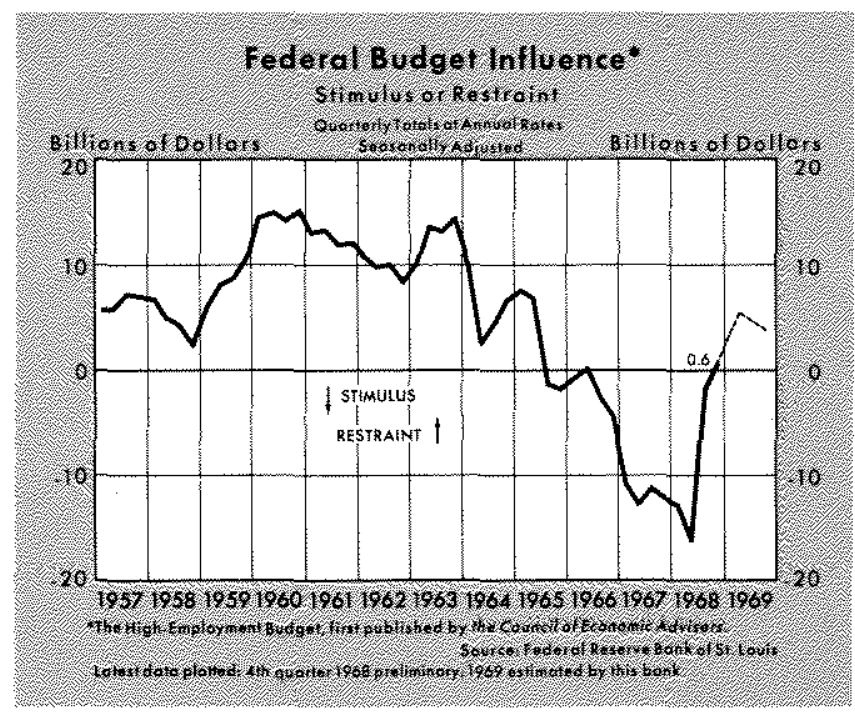

moved from a very large deficit $(\$ 16.1$ billion annual rate) in the second quarter 1968 to a small surplus ( $\$ 0.6$ billion annual rate) in late 1968. The delay in the passage of the Revenue and Expenditure Control Act contributed to the over-all growth of revenue to the extent that inflation was allowed to intensify before action was taken, thereby adding to Government tax receipts.

Monetary expansion was very rapid in 1968. The nation's money stock rose 6.5 per cent from December 1967 to December 1968, about the same as the previous year, compared with a trend rate of 3.5 per cent from 1961 to 1967 . The monetary base increased 6.4 per cent in 1968 , about the same as the previous year but greater than the 4.5 per cent average annual rate from 1961 to 1967.

\section{Evaluation of the 1968 Economic Plan}

The 1968 CEA Report projected a 7.8 per cent advance of total spending for calendar 1968; the actual increase was 9 per cent. The CEA anticipated a rapid advance in the first half followed by a more moderate expansion in the second half. In fact, spending grew faster than anticipated in both halves of the year. 


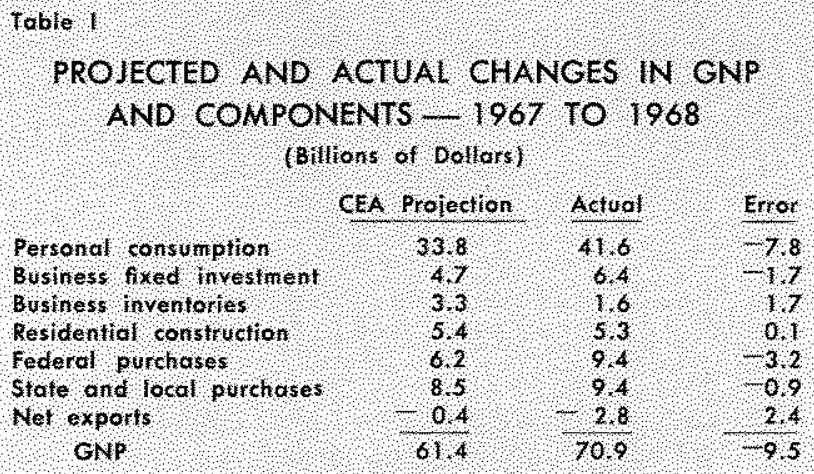

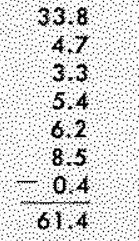

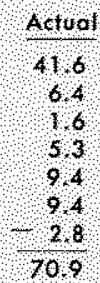

The CEA error of $\$ 9.5$ billion for the year consisted primarily of underestimates of consumption and Federal purchases. With final spending on domestic goods and services much greater than projected, inventory accumulation and net exports (exports minus imports) were overestimated.

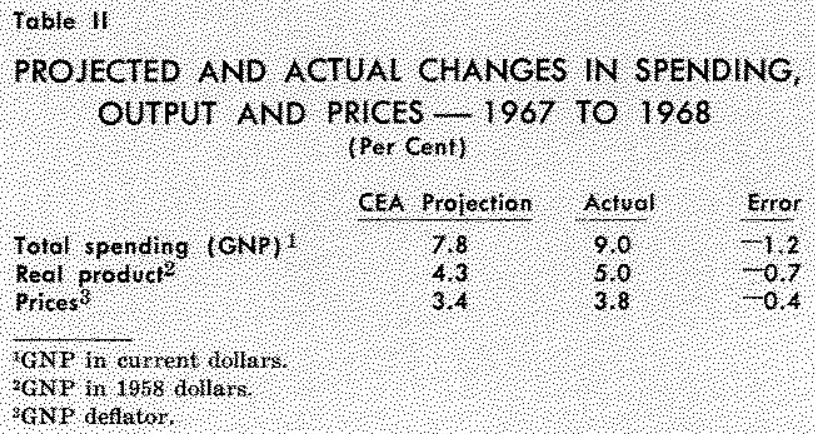

GNP in anment dellars ${ }^{2} \mathrm{GNP}$ fo 1968 dolars GNP defator.

The GNP projected for 1968 can also be evaluated in terms of anticipated growth of real product and advance of prices. Real product was forecast to increase 4.3 per cent and actually rose 5 per cent. Price advances were similarly underestimated. Prices were projected to rise 3.4 per cent and actually increased 3.8 per cent.

To determine the underlying source of error, fiscal and monetary plans are compared with actions. The CEA has indicated that its error in projecting economic activity was traceable in large part to delayed passage of the tax surcharge. However, an examination of the national income accounts budget re-

Toble III

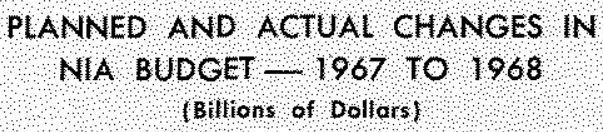

\begin{tabular}{|c|c|c|c|}
\hline & Budget Plan & Actual & Error \\
\hline Receipts & 228 & 25.7 & 3.1 \\
\hline Expenditures & 149 & 186 & $\begin{array}{r}3.7 \\
0.6\end{array}$ \\
\hline
\end{tabular}

veals that the actual deficit was little different from the anticipated deficit. Federal expenditure growth was more rapid than anticipated, but so was the growth of receipts. Such a comparison is misleading, however, because receipts reflected the rapid advance of incomes, which is a reflection of inflation rather than fiscal restraint. This underestimation of income growth may account for the bulk of the $\$ 3.1$ billion error in the receipts estimation. Taking into account this effect, the error in the estimate of the NIA deficit may have been, more accurately, $\$ 3$ to $\$ 4$ billion. It seems unlikely, however, that this error would be sufficient to explain the $\$ 9.5$ billion error in the CEA's estimate of GNP for 1968 .

The second possible source of error was in estimating the effect of monetary actions. An explicit assumption about monetary actions was not specified in the I968 Economic Report. If it were asumed, however, that the CEA anticipated about a 4 per cent growth in the money stock, their forecast went awry because the realized growth in money stock was 6.5 per cent.

The empirical importance of the growth of money stock in the determination of the growth of total spending has been suggested in a previous issue of this Review. ${ }^{3}$ The policy oriented model presented

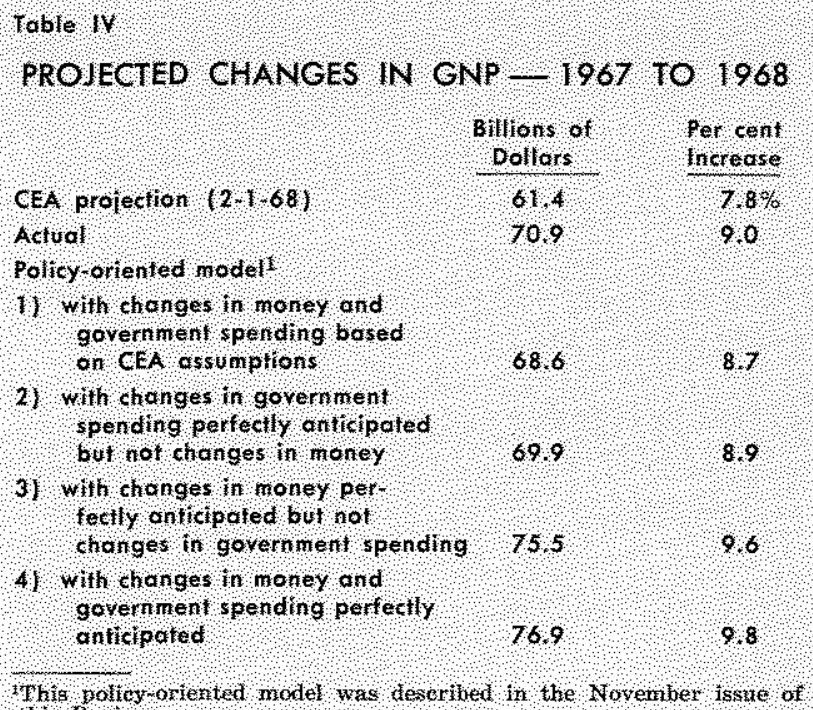

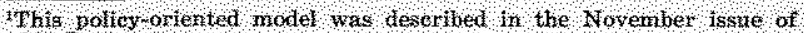
this rewter

there, given the information available at the time of the preparation of the 1968 Economic Report and assuming a 4 per cent growth in money, would have predicted an 8.7 per cent increase in GNP for 1968.

3See "Monetary and Fiscal Actions: A Test of Their Relative Importance in Economic Stabilization" in the November 1968 issue of this Review. 
As it turned out, that model, too, would have underestimated growth in total spending because it underestimated growth in money. It's error would have been $\$ 2.3$ billion, compared with the CEA error of $\$ 9.5$ billion. When the actual growth of money is inserted in the forecasting equation, the predicted increase would have been $\$ 75.5$ billion, or $\$ 4.6$ billion more than realized. In other words, the policyoriented model would have predicted a 9.6 per cent increase in GNP, compared with an actual increase of 9 per cent.

In short, the CEA's forecast for 1968 was too low, an error which is particularly costly in an inflationary situation. There are two key reasons for this error. First, the growth of Federal expenditures was underestimated and the surtax was passed later than planned. Second, the effect of monetary actions was evidently underestimated. The effect of a given change in money apparently was not properly taken into account, and the rate of growth of money was underestimated. Based on the 1968 experience, however, the policy-oriented model which was used for comparative purposes slightly overestimated the effect of monetary actions.

\section{Policy and the Economic Outlook for 1969}

Budget plans for the 18-month period ending June 30,1970 are formulated with the view that fiscal restraint is necessary to reduce inflationary pressures, and that there is merit in stabilizing the high-employment budget in balance or slight surplus. Given this budget program, the CEA expects total spending to slow in 1969. Whether such a slowing will occur depends largely on the fiscal program ultimately adopted by Congress and the new Administration, and the forthcoming rate of monetary expansion.

\section{Federal Budget Program for 1969}

The proposed budget of the Federal Government for calendar 1969 results in a budget surplus of $\$ 3.8$ billion on a NIA basis. Budget plans include provisions to increase expenditures 5.5 per cent during 1969 and to extend the 10 per cent tax surcharge through June 1970 .

Expenditures - The budget plan of a 5.5 per cent rise in spending during 1969 is down sharply from the 10.8 per cent increase during the previous year. Federal spending rose at a 15.1 per cent average annual rate from 1965 to 1967 and a 4.9 per cent average rate from 1961 to 1965.
Defense spending is projected to change little in 1969 , following a 7.2 per cent increase in 1968. The average rate of advance from 1965 to 1967 was 20.2 per cent. Estimates of defense spending for 1969 reflect a planned decline in expenditures for support of Vietnam operations.

Federal spending on civilian programs, i.e., nondefense spending, is budgeted to rise 8.1 per cent during 1969. This rate of increase is less than the 13.6 per cent rate of advance during 1968 and the 11.5 per cent rate from 1965 to 1967 . Nondefense spending rose at a 7.8 per cent rate from 1961 to 1965 . The increase in domestic spending in 1969 reflects a pay increase for government employees effective July 1.

Receipts - Federal receipts are expected to rise commensurate with the increase in spending. Extension of the 10 per cent tax surcharge is required to keep the budget in surplus in 1969. The increase in receipts during 1969 consists of $\$ 3$ billion from changes in tax rates and $\$ 10$ billion expected to be produced by growth in the economy.

\section{CEA Projection for 1969}

The fiscal program proposed by the outgoing Administration, and apparently adopted by the present Administration, is supposedly consistent with a 7 per cent growth of total spending in 1969. The former CEA projected a slowing of total spending in the first half of 1969 , followed by acceleration in the second half. The present CEA indicated in their statement to the Joint Economic Committee that the slowing in the first half may not be so pronounced, and that the anticipated acceleration in the second half should be checked by monetary actions.

The present Council has further judged that the 7 per cent growth in total spending would be manifested in a 3.4 per cent growth in real product and a 3.5 per cent advance in prices. This evaluation, however, runs contrary to recent experience in the United States. In the period from 1954 to present, all major slowdowns in the growth of total demand have been accompanied by simultaneous deceleration of real output growth, followed three or four quarters later by a slowing in the rate of price increase.

In view of the former CEA's forecasting errors in 1968, the estimates for 1969 should be subjected to careful review. No specific recommendations are made

4See "Stabilization Policy and Inflation" in the February 1969 issue of this Review. 


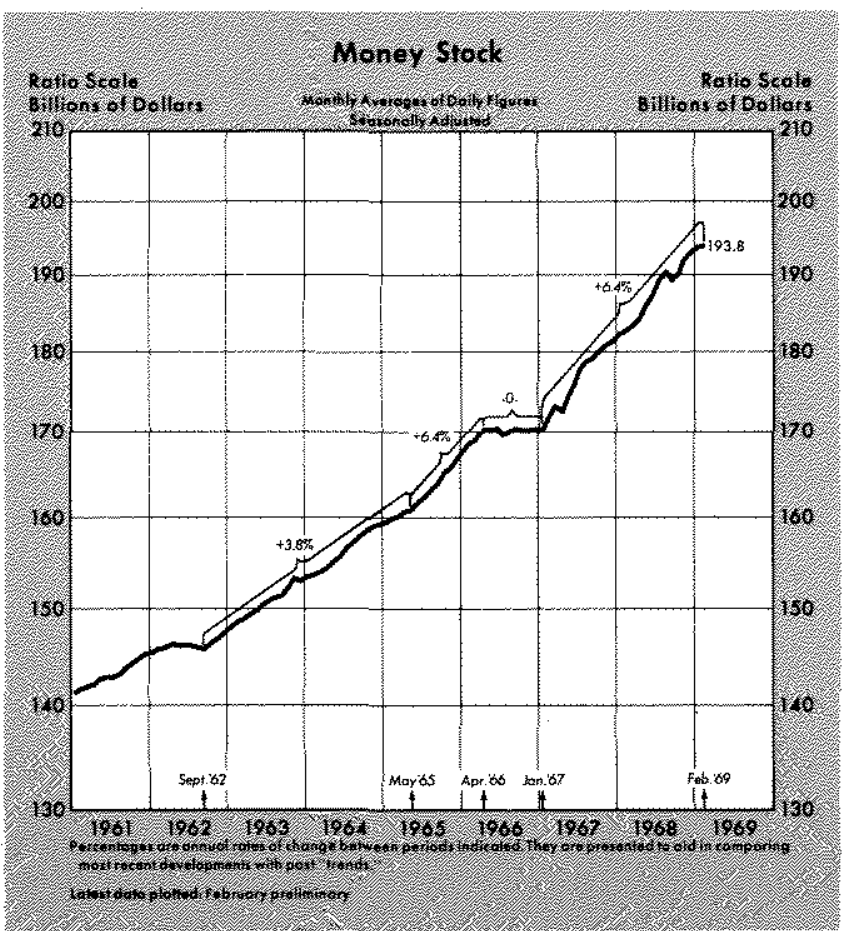

in either the CEA Report or in the CEA statement before the Joint Committee about monetary actions other than that they should be appropriate. In view of the tone of restraint in the Report and the present Coun-

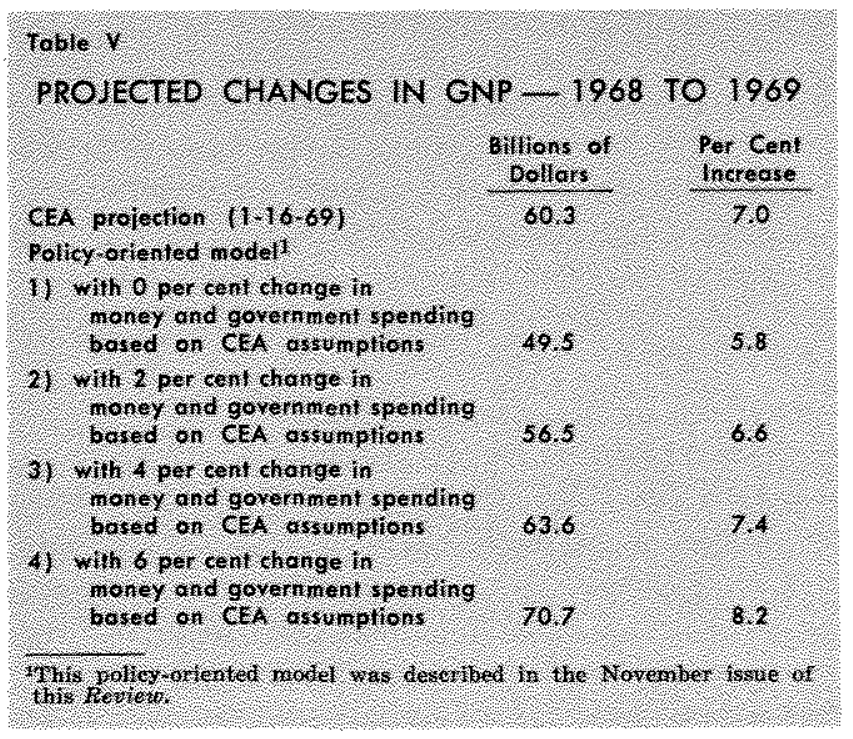

This article is available as Reprint No. 35 cil's statement before the Joint Economic Committee, it might be assumed that a 4 per cent growth in money in 1969 would represent a policy of moderate monetary restraint without being so restrictive as to drive the economy into recession.

To gain some understanding of the alternatives that seem to be forthcoming, the policy-oriented forecasting model of this bank may be examined. This model would yield an increase in total spending similar to the CEA's projection if money grew at about a 3 per cent rate. A steady 4 per cent growth in money would yield a 7.4 per cent growth in total spending. These estimates are quite close to the CEA forecast, and indicate that the CEA forecast may be achievable if money is slowed to about a 3 or 4 per cent rate of advance. Even if a slowing in the rate of monetary expansion were apparent by spring 1969 , little should be expected in the way of reduction in the rate of price advance before late 1969 .

\section{Summary}

The former and present Councils have appropriately outlined a program of fiscal restraint for 1969. As in the past, however, little emphasis has been placed on the crucial role of monetary actions in the determination of the growth of total demand. There is some indication, however, that the present CEA is aware of the influence of monetary actions, though the case was not strongly presented in the Joint Committee statement.

The economic program for 1969, which calls for some moderation in demand growth, presents objectives which may be achievable if accompanied by a reduction in the growth of monetary aggregates from the rapid rates of increase in 1968. If the rate of monetary expansion is not reduced to these slower rates, given the proposed budget plan, the projection would probably prove low, as in 1968. On the other hand, if monetary expansion should be replaced by no growth or contraction, and the fiscal program is implemented as planned, the projection of spending growth is likely to be high. 